\title{
Dyslipidemia Associated with Chronic Kidney Disease
}

\author{
Vasilis Tsimihodimos, Zoi Mitrogianni and Moses Elisaf*
}

Department of Internal Medicine, Medical School, University of Ioannina, Ioannina, Greece

\begin{abstract}
Cardiovascular disease is a major cause of morbidity and mortality in patients with impaired renal function. Dyslipidemia has been established as a well-known traditional risk factor for cardiovascular disease (CVD) in the general population and it is well known that patients with chronic kidney disease (CKD) exhibit significant alterations in lipoprotein metabolism. In this review, the pathogenesis and treatment of CKD-induced dyslipidemia are discussed. Studies on lipid abnormalities in predialysis, hemodialysis and peritoneal dialysis patients are analyzed. In addition, the results of the studies that tested the effects of the hypolipidemic drugs on cardiovascular morbidity and mortality in patients with CKD are reported.
\end{abstract}

Keywords: Chronic kidney disease; renal failure; dyslipidemia; hypertriglyceridemia; hemodialysis; peritoneal dialysis.

\section{INTRODUCTION}

Chronic kidney disease (CKD) is a significant health problem. It was estimated that the prevalence of CKD among the USA population between 1999-2004 was $15.3 \%$ [1]. On the other hand, it is well documented that cardiovascular disease (CVD) is a major cause of morbidity and mortality in patients with CKD [2-6]. Thus, although some patients with CKD will ultimately develop end stage renal disease (ESRD), most patients with CKD will die of CVD before dialysis becomes necessary [7]. Mild chronic impaired renal function contributes actively to the development of CVD, so the American Heart Association has recommended that these patients should be classified in the highest risk group for developing cardiovascular events [5]. Even microalbuminuria in the absence of apparent deterioration in renal function or diabetes predicts more CVD and deaths [8]. In patients who finally advance to ESRD and especially dialysis patients, the prevalence of clinical coronary heart disease is $40 \%$ and CVD mortality is 10 to 30 times higher than in the general population of the same gender, age and race $[5,9$, 10].

Several factors contribute to atherogenesis and CVD in patients with CKD [11]. Although most of the cases of coronary heart disease in the general population can be explained by traditional, Framingham risk factors [12], in patients with $\mathrm{CKD}$, uremia related, non -traditional risk factors, such as, inflammation, oxidative stress, anemia, malnutrition, vascular calcification (due to alterations in calcium and phosphorus metabolism) and endothelial dysfunction have been proposed to play a central role [13]. However, studies investigating the usefulness of current CVD biomarkers have concluded that they add only moderately to traditional risk factors for risk assessment in individuals with almost normal

*Address correspondence to this author at the Department of Internal Medicine, Medical School, University of Ioannina, 45110 Ioannina, Greece;

Tel: +30-2651-0-07509; Fax: +30-2651-0-07016;

E-mail: egepi@cc.uoi.gr renal function [14] as well as patients with mild to moderate CKD $[15,16]$.

Notable among the traditional risk factors for CVD in the general population is dyslipidemia. Several observational studies have shown that total and LDL-cholesterol values are two of the most important independent predictors of cardiovascular morbidity and mortality [17]. Also, it is well known that patients with impaired renal function exhibit significant alterations in lipoprotein metabolism, which in their most advanced form may result in the development of severe dyslipidemia. However, the precise role that these alterations play in the pathogenesis of atherosclerosis in individuals with CKD remains controversial. In this review studies on the pathogenesis of CKD-induced dyslipidemia in predialysis and dialysis patients with impaired renal function and the results of drug therapy are discussed.

\section{PATHOPHYSIOLOGY OF CKD-INDUCED DYSLIPI- DEMIA}

CKD is characterized by specific metabolic abnormalities of plasma lipoproteins $[18,19]$. These abnormalities involve all lipoprotein classes and shows variations depending on the degree of renal impairment, the etiology of primary disease, the presence of nephrotic syndrome (NS) and the method of dialysis [hemodialysis (HD) or peritoneal dialysis (PD)] for patients undergoing renal replacement therapy.

\section{ALTERATIONS OF TRIGLYCERIDE-RICH LIPO- PROTEIN METABOLISM IN PREDIALYSIS AND DIALYSIS PATIENTS WITH CKD}

Hypertriglyceridemia is one of the most common quantitative lipid abnormalities in patients with CKD [20-22]. The concentrations of triglyceride-rich lipoproteins [very-lowdensity lipoprotein (VLDL), chylomicrons, and their remnants] start to increase in early stages of CKD and show the highest values in NS and in dialysis patients, especially those who are treated with PD. 
Several studies have shown that patients with impaired renal function exhibit increased concentrations of triglycerides even though serum creatinine levels are within normal limits [23, 24]. Also, individuals with CKD usually display abnormal increases in serum triglyceride levels after a fat meal (postprandial lipemia) [25]. The predominant mechanism responsible for increased concentration of triglyceriderich lipoproteins in predialysis patients is one of delayed catabolism [26]. The reduced catabolic rate is likely due to diminished lipoprotein lipase activity as a consequence of the downregulation of the enzyme gene [27] and the presence of lipase inhibitors [28]. Apolipoprotein C-III is a potent inhibitor of lipoprotein lipase whereas apolipoprotein $\mathrm{C}$ II is an activator of the same enzyme. A decrease in apolipoprotein $\mathrm{C}$-II/C-III ratio due to a disproportionate increase in plasma apolipoprotein C-III is a possible cause of lipoprotein lipase inactivation in uremia [29-32]. It was also suggested that secondary hyperparathyroidism is involved in the impaired catabolism of triglyceride-rich lipoproteins, provided an additional mechanism by which CKD may raise plasma triglyceride concentrations [33, 34]. Except of the low catabolic rate, the increased hepatic production of triglyceriderich lipoproteins may also play a contributory role in the pathogenesis of dyslipidemia in renal disease [26]. It is well known that CKD causes insulin resistance which can, in turn, promote hepatic VLDL production [23-25]. Thus, it could be hypothesized that the insulin resistance-driven overproduction of VLDL may significantly contribute to the development of hypertiglyceridemia in patients with CKD.

Hypertiglyceridemia [due to accumulation of VLDL and remnant lipoproteins such as intermediate-density lipoprotein (IDL)], is also the predominant lipoprotein abnormality in a considerable number of cases with nephrotic range proteinuria [35]. This dyslipidemia results from a combination of increased production and reduced clearance of VLDL [36]. It is well known that the progressive delipidation of triglyceride-rich lipoproteins is facilitated by the action of two different enzymes namely endothelial-bound lipoprotein lipase and hepatic lipase. The expression of the genes of these enzymes has been found to be downregulated in patients with NS [37]. In addition, other factors such as hypoalbuminemia and proteinuria may further decrease the efficiency of lipoprotein lipase-induced lipolysis of triglyceride-rich lipoproteins by interfering with the endothelial binding of the enzyme and by changing the composition of VLDLs in a way that reduces their suitability as lipoprotein lipase substrates, respectively [38].

The initiation of renal replacement therapy, as well as the choice of dialysis modality, may also influence the levels of triglyceride-rich lipoproteins in ESRD patients [39]. The pathophysiological mechanisms responsible for these alterations seem to be generally similar with those described in predialysis patients with CKD. However, factors related to the procedure of renal replacement therapy seem to contribute to the increased levels of triglycerides observed in this patient group. In HD patients the repeated use of lowmolecular heparins for anticoagulation may lead to a defective catabolism of triglyceride-rich lipoproteins as heparin releases lipoprotein lipase from the endothelia surface and thus its chronic use may result in lipoprotein lipase depletion. However, the studies that tested the role of heparin in the pathogenesis of HD-induced dyslipidemia revealed con- tradictory results [40-42]. In addition, controversy exists as to whether low-molecular weight heparins have a more favorable effect on the lipid profile of HD patients compared to standard unfractionated heparin [43, 44]. Also, studies on the influence of the type of membrane used in HD yielded conflicting results. It has been shown that the use of highflux polysulfone or cellulose triacetate membranes is accompanied by a significant reduction in serum triglyceride. This improvement could, at least in part, be attributed to an increase in the apolipoprotein C-II/CIII ratio which increases the activity of lipoprotein lipase and facilitates the intravascular lipolysis of triglyceride-rich lipoproteins [45]. However, other studies suggest that the type of dialysis membrane does not influence the characteristics of dyslipidemia [46].

In contrast to HD patients, hypertiglyceridemia is more prevalent in continuous ambulatory peritoneal dialysis (CAPD) patients [47]. Although the pathophysiological mechanisms are not clear, it has been suggested that the significant absorption of glucose from the dialysis fluid may play a significant role as it can lead to an increase in insulin levels and may enhance the hepatic synthesis and secretion of VLDL [48]. Although no direct correlation has been observed between peritoneal glucose absorption and serum lipid levels in peritoneal dialysis patients, recent studies indicate that the reduction of glucose load with the use of less absorbed icodextrin-containing dialysis solution instead of glucose for the overnight dwell, sufficiently improves the lipid profile of these patients $[49,50]$.

\section{ALTERATIONS IN LOW DENSITY LIPOPROTEIN (LDL) METABOLISM IN PREDIALYSIS AND DI- ALYSIS PATIENTS WITH CKD}

Plasma total cholesterol is usually normal or reduced and occasionally elevated in ESRD patients. A significant factor which determines the levels of plasma cholesterol-rich lipoproteins, except of the deterioration in renal function, is the degree of proteinuria. Chronic kidney disease in the absence of heavy proteinuria does not significantly affect gene expressions of either hydroxyl-3-methylglutaryl-CoA reductase (HMG-CoA reductase) which is the rate-limiting enzyme for cholesterol biosynthesis, or that of cholesterol $7 \mathrm{a}$ hydroxylase which is the rate-limiting enzyme for cholesterol catabolism and conversion to bite acids [51]. Also, LDL receptor-mediated cholesterol uptake plays an important role in cholesterol homeostasis. CKD in the absence of heavy proteinuria or significant glomerulosclerosis does not alter hepatic LDL receptor gene expression [51]. In contrast, patients with nephrotic range proteinuria, exhibit an acquired LDL-receptor deficiency [52]. Although the nature of this deficiency has not been fully characterized, studies in experimental animals have shown that the inefficient translation and/or the increased LDL-receptor protein turnover may represent the most important causes for its development [53, 54]. In addition to these mechanisms, conformational changes in the apolipoprotein B moiety of LDLs may further reduce the affinity of $\mathrm{LDL}$ particles for $\mathrm{LDL}$ receptor thus contributing to the elevated LDL-cholesterol levels that represent the prominent feature of nephrotic dyslipidemia [55]. The reduced receptor-mediated catabolism of LDL particles along with the upregulation of acyl-coenzyme A: cholesterol acyltransferase (ACAT) gene (the enzyme responsible for 
cholesterol esterification in hepatocytes) that has been observed in individuals with NS [56] may reduce the free cholesterol content of hepatocytes and thus may lead to the dysregulation of the key enzymes that are involved in cholesterol homeostasis. Indeed, studies in animals with experimental nephrosis revealed an upregulation of $\mathrm{HMG}-\mathrm{CoA}$ reductase [57] as well as a relative reduction of cholesterol $7 \alpha$-hydroxylase [58]. All the aforementioned mechanisms in concert may result in the increased concentration of LDLcholesterol in individuals with NS.

Chronic kidney disease patients, with or without heavy proteinuria, display important qualitative alterations in LDL metabolism. The proportion of small dense LDL particles, which is considered to be highly atherogenic, is increased $[59,60]$. Small dense LDL is a subtype of LDL that has high propensity to penetrate the vessel wall, becomes oxidized and triggers the atherosclerotic process.

In HD patients the serum lipid concentrations resemble those of predialysis patients with CKD, which means that total and LDL cholesterol levels are generally normal, whereas the subfractionation of apolipoprotein B-containing lipoproteins usually reveals a predominance of small dense particles $[60,61]$. On the other hand, CAPD patients exhibit a more atherogenic lipid profile that is characterized by higher total and LDL cholesterol values and increased concentrations of small dense LDL and apolipoprotein B [47, $60,62]$. A number of possible factors associated with the PD treatment may explain those alterations in lipoprotein metabolism. It is known that CAPD patients lose substantial amounts of plasma proteins into the peritoneal dialysate. This protein loss may, in turn, stimulate the hepatic synthesis of albumin and other liver-derived proteins, including cholesterol-enriched lipoproteins [63-65]. It should be also mentioned that, in CAPD patients, substantial amounts of apolipoproteins and intact lipoproteins are lost via the peritoneal cavity. However the pathophysiological significance of these loses remains unclear $[66,67]$.

Finally, recent studies have investigated the role of the administration of the phosphate-binding resin sevelamer hydrochloride in the levels of plasma cholesterol and apolipoprotein B in HD and PD patients. It has been shown that sevelamer hydrochloride significantly reduces the concentrations of total cholesterol and apolipoprotein B in HD patients [68]. Obviously, the cholesterol-lowering properties of this compound are irrelevant to phosphate reduction and can be mainly attributed to its bile acid sequestrating properties, resembling cholestyramine effect. It is likely that the use of sevelamer would result in a similar effect in CAPD patients.

\section{LIPOPROTEIN (a) (LP(a)) AND CKD}

$\mathrm{Lp}$ (a) represents an LDL-like particle distinguished from LDL by the presence of apolipoprotein(a) [apo(a)], which is attached to apolipoprotein B-100 molecule through disulfide linkage [69]. Apo(a) is highly homologous to the plasma protease zymogene plasminogen and thus it has been suggested that $\mathrm{Lp}$ (a) may promote thrombogenesis by inhibiting fibrinolysis [69]. Studies in healthy individuals and in patients with CKD have shown that serum Lp(a) levels are strongly and negatively associated with apo(a) isoform size. Indeed, subjects who have low molecular weight (LMW) apo(a) isoforms show on average higher $L p(a)$ concentra- tions compared to those who have high molecular weight (HMW) isoforms [70]. The large concentration gradient of $\mathrm{Lp}$ (a) between aorta and the renal vein [71] as well as the identification of apo(a) fragments in urine [72] suggest that the kidney may actively participate in the degradation of $\mathrm{Lp}(\mathrm{a})$. Thus, it is not surprising that patients with primary kidney diseases (even those with normal GFR values) usually exhibit markedly elevated concentrations of $\operatorname{Lp}(\mathrm{a})$ [73, 74] as well as increased concentrations of LDL-unbound apo(a) [75]. However, recently published studies indicate that the negative association between renal function and $\mathrm{Lp}$ (a) levels is phenotype-specific. Thus, predialysis CKD patients with HMW apo(a) isoforms tend to have much higher Lp(a) values than apo(a) phenotype-matched healthy controls, whereas patients with kidney diseases who exhibit LMW apo(a) isoforms have similar $\mathrm{Lp}(\mathrm{a})$ concentrations with phenotype-matched healthy individuals, who already have high $\operatorname{Lp}(a)$ levels $[69,76]$. It is worth mentioning that prospective studies identified small apo(a) isoform size and not $\mathrm{Lp}$ (a) level as an independent predictor of total and cardiovascular mortality in patients with CKD [77, 78].

The isoform-specific increase in plasma $\mathrm{Lp}(\mathrm{a})$ was also observed in HD patients $[79,80]$. The malnutrition and inflammation and, mainly, the decreased clearance of apo(a) in HD patients, have been implicated in this procedure [80-83]. In contrast, in CAPD patients, increases in plasma $\mathrm{Lp}(\mathrm{a})$ levels occur in all apo(a) isoform groups, probably as a consequence of the pronounced protein loss and the subsequently increased production of this lipoprotein in the liver [79, 84, 85]. Similarly to CAPD patients, individuals with nephrotic range proteinuria exhibit increased concentrations of $\mathrm{Lp}(\mathrm{a})$ that is not phenotype-specific $[86,87]$.

\section{HIGH DENSITY LIPOPROTEIN (HDL) AND CKD}

The main function of HDL is the transport of surplus cholesterol from the arterial wall to the liver for excretion. This process, which is commonly called 'reverse cholesterol transport', is critical for cellular cholesterol homeostasis and protection against atherosclerosis. Moreover, HDL serves as a potent endogenous inhibitor of inflammation, platelet adhesion and LDL oxidation, because of a number of HDL associated apolipoproteins (mainly apolipoprotein AI) and enzymes (paroxonase-1, platelet-activating factor acetylhydrolase and lecithin-cholesterol acyltransferase (LCAT) [88]. Several epidemiological studies have demonstrated that HDL cholesterol is a negative risk factor for atheroscerosis [89]. Patients with CKD have, generally, reduced plasma HDLcholesterol levels compared to individuals with normal renal function [19, 90, 91]. This can be attributed to several mechanisms. Thus, patients with impaired renal function usually exhibit decreased levels of apolipoproteins AI and AII (the main protein constituents of HDL) [91], diminished activity of LCAT (the enzyme responsible for the esterification of free cholesterol in HDL particles) [92, 93], as well as increased activity of cholesteryl ester transfer protein (CETP) [94] that facilitates the transfer of cholesterol esters from HDL to triglyceride-rich lipoproteins thus reducing the serum concentrations of HDL-cholesterol. In addition to their reduced efficiency as cholesterol acceptors, HDL particles from individuals with impaired renal function have less effective antioxidative and anti-inflammatory function. This impairment can, at least in part, be attributed to the reduction 
in the activities of HDL-associated enzymes, such as paraoxonase (an enzyme that inhibits the LDL oxidation) [95, 96].

Hemodialysis and PD procedure may also have a contributory role in the reduced HDL cholesterol levels of dialysis patients [39, 47]. Thus, in dialysis patients the type of membrane and dialysate used in HD procedure may influence the HDL-cholesterol levels. It has been shown that the use of high-flux instead of low flux membranes is associated with an increase in apolipoprotein AI and HDL-cholesterol values. [97, 98]. In addition, the type of dialysate may also significantly affect the serum levels of lipoproteins in HD patients. Indeed, it has been shown that the use of bicarbonate dialysate may result in higher HDL-cholesterol concentrations than the use of acetate dialysate [99].

\section{DYSLIPIDEMIA AS A RISK FACTOR FOR CARDIO- VASCULAR DISEASE IN CKD}

It is well known that dyslipidemia represents an important (maybe the most important) risk factor for the development of cardiovascular disease (CVD) in the general population. Indeed, large-scale epidemiological studies revealed a lineal relationship between total and LDL-C values and the incidence of ischemic events in both primary and secondary prevention individuals, whereas the reduction in the concentrations of these parameters by means of diet, drug therapy or surgery is followed by an impressive reduction in the future cardiovascular risk [17]. On the other hand, the role of dyslipidemia in the pathophysiology of atherosclerotic disease in patients with impaired renal function remains controversial. Thus, some studies have shown a positive association between cholesterol values and the risk for cardiovascular events in CKD individuals [100], whereas others failed to find any significant correlation [101, 102]. Finally, some other studies suggested an inverse relationship between serum cholesterol values and mortality in ESRD individuals, a phenomenon also known as "reverse epidemiology" [101, $103,104]$. Although the precise causes of this significant deviation from what is observed in the general population have not been established, it has been proposed that the presence of phenomena such as inflammation or protein energy wasting (conditions very common in ESRD patients) may significantly confound the relationship between the traditional risk factors for CVD and mortality in this patient population $[105,106]$. In other words, ESDR patients free of these complications behave exactly as individuals with normal renal function, whereas in the presence of these conditions low rather than high cholesterol values predict a poor outcome. [105, 106]. In agreement with this hypothesis the statistical adjustment for markers of inflammation and/or malnutrition in some studies restores the positive association between serum cholesterol values and mortality in CKD individuals[105, 106]. However, it must be mentioned that the aforesaid assumptions were not confirmed by the results of recent studies. Indeed, Kilpatrick et al. [107] in a cohort of 15.859 HD patients showed that the positive relationship between cholesterol values and cardiovascular death risk may be confined to certain racial subgroups such as black HD patients. These discrepancies clearly show that further studies are needed to delineate the impact of lipoprotein concentrations on total and cardiovascular risk in individuals with ESRD.

\section{DYSLIPIDEMIA AS A THERAPEUTIC TARGET IN CKD}

Despite the uncertainty that surrounds the role of dyslipidemia in the pathogenesis of atherosclerotic disease in CKD individuals, based on the extremely high cardiovascular mortality that characterizes this patient population, the Work Group for Kidney Disease Outcomes Quality Initiative (K/DOQI) proposed the adoption of Adult Treatment Panel (ATP) III LDL-cholesterol targets for individuals with ESRD and suggest the aggressive treatment of lipid disorders $[108,109]$. However, recent studies indicate that the use of lipid-lowering medications in individuals with impaired renal function is limited, whereas a small minority of those receiving hypolipidemic drugs achieves therapeutic targets $[110,111]$. It is possible that the most important factor that limits the use of hypolipidemic drugs in individuals with CKD is the contradictory results of the studies that tried to delineate the effects of statins on total and cardiovascular mortality in this patient population. It is well known that statins are by far the most commonly prescribed hypolipidemic drugs in the general population and numerous large, randomized, prospective studies have shown that their use is accompanied by an impressive reduction in the incidence of cardiovascular events [112]. On the other hand, the beneficial effect of statin administration on cardiovascular morbidity and mortality in individuals with CKD seems to be related to the severity of renal dysfunction. Indeed, in several large, prospective, placebo-controlled trials of statins, post hoc analyses of subgroups with mild to moderate CKD (stages 1-3) revealed a significant reduction in cardiovascular morbidity and mortality independently of the baseline lipid values and the presence or the absence of diabetes and coronary artery disease [113-118]. The same results were also obtained by the study of the prespecified subgroups of individuals with impaired renal function in the HPS [109, 119] and ASCOT-LLA [120] studies that utilized simvastatin and atorvastatin, respectively. A recently published metaanalysis that included 26 studies (about 25.000 participants) revealed that the use of statins in predialysis individuals with CKD is followed by a significant reduction in allcause and cardiovascular mortality by approximately $20 \%$ [121]. Interestingly, the rate of adverse events was similar in patients receiving statins and placebo. These results suggest that the use of statins for the prevention of ischemic events in dyslipidemic individuals with early CKD seems to be a safe, reasonable and evidence-based approach.

Although epidemiological studies have shown that the use of statins in individuals receiving maintenance hemodialysis is accompanied by a reduction in cardiovascular mortality [122-124], the prospective, randomized trials that tested the potential beneficial effect of statins in this patient population revealed disappointing results. The 4D (Die Deutsche Diabetes Dialyse) trial enrolled 1255 diabetic subjects who had been on maintenance HD for less than 2 years and were randomized to receive either placebo or $20 \mathrm{mg} /$ day of atorvastatin [125]. Overall, after a mean follow-up period of 2.4 years atorvastatin did not significantly reduce the risk of the composite primary end point (cardiovascular death, nonfatal myocardial infarction and stroke), despite a significant $42 \%$ reduction in LDL-cholesterol concentration [126]. Although this study had several potential limitations [the 
majority of cardiovascular events were possibly nonischemic in nature, a significant proportion of individuals in the placebo arm (about 15\%) also received a non-study statin, the study was conducted exclusively in patients with diabetes mellitus and the extrapolation of its findings to nondiabetic subjects was questionable etc], it raised important concerns about the efficacy of statin administration in individuals with ESRD. Similar findings were also reported in a small Scandinavian study that showed a significant decrease of cardiovascular end points after atorvastatin administration in predialysis patients with CKD but no effect in individuals who were on maintenance HD [166].

The publication of the results of AURORA (A Study to Evaluate the Use of Rosuvastatin in Subjects on Regular Hemodialysis: An Assessment of Survival and Cardiovascular Events) study few months ago [127], led to the conception of "a point of no return", i.e. a point in the deterioration of renal function beyond which the beneficial effect of statins in cardiovascular morbidity and mortality is offset by the uremic environment. AURORA study was a prospective, double-blind trial involving 2775 individuals on maintenance HD who were randomized to receive $10 \mathrm{mg}$ of rosuvastatin per day or placebo. After a median follow-up period of 3.8 years, and despite the impressive reduction in LDL-C and Creactive protein concentrations (by 43 and $11.5 \%$, respectively), rosuvastatin administration had no effect on the primary composite end-point (nonfatal myocardial infarction, nonfatal stroke and cardiovascular death) or the individual components of the primary end-point. There was also no significant effect on all-cause mortality while none of the pre-specified secondary outcomes was influenced by active treatment.

Several mechanisms have been proposed for the explanation of the failure of statins to improve cardiovascular outcomes in individuals with advanced CKD. Thus, it has been suggested that the initiation and progression of atherosclerotic disease in this population may have a different pathophysiological basis (arterial wall calcification, inflammation etc), whereas other investigators emphasize that lipoproteins other than LDL (such as Lp(a), IDL etc) may play significant role in the initiation and progression of coronary atherosclerosis $[22,128,129]$. Whatever the cause, it seems that in this patient population the decision for the administration of statins should be individualized.

Fibric acid derivatives (fibrates) represent another important class of hypolipidemic medications. These drugs modify the expression of genes involved in lipoprotein metabolism and thus they reduce the concentrations of triglycerides, increase the serum concentrations of HDL-cholesterol and induce a shift in LDL subfraction distribution towards larger and more buoyant particles [130]. Thus, theoretically, these drugs could represent an ideal option for the treatment of uremic dyslipidemia. However, it has been shown that the administration of fibrates (possibly with the exception of gemfibrozil) in individuals with impaired renal function is associated with an extremely high risk of muscular toxicity $[131,132]$. In addition, these drugs also significantly increase serum creatinine values. Although it has been proposed that this increase does not represent a true deterioration in renal function but rather is due to increased metabolic production of creatinine, cases of nonreversible renal failure have been reported after fibrate administration [131]. In addition, the effect of fibrates on cardiovascular morbidity and mortality in individuals with impaired renal function has not been extensively studied. Thus, although an observational study suggested that the use of fibrates in patients with impaired renal function does not reduce total mortality [122], a post hoc analysis of the secondary prevention VA-HIT study revealed that the administration of gemfibrozil in individuals with moderate $\mathrm{CKD}$ reduced the risk of the primary end point (coronary death or nonfatal myocardial infarction) by $27 \%$ [133]. For these reasons, it seems reasonable that fibrates should be used only in the subpopulation of patients with CKD who exhibit extremely high triglycerides values (greater than $500 \mathrm{mg} / \mathrm{dl}$ )[131]. In these cases, the risk of acute pancreatitis justifies the use of gemfibrozil that is the fibrate of choice in individuals with impaired renal function [131]. The administration of omega-3 polyunsaturated fatty acids may also have a role in the management of this extremely rare condition [134].

A number of other hypolipidemic drugs that are increasingly used in the general population (such as niacin, omega-3 polyunsaturated fatty acids and ezetimibe) may also have important roles in the management of uremic dyslipidemia. However, although small studies have documented the biochemical efficiency and the tolerability of these substances in patients with chronic kidney disease, no prospective studies with clinical end-points have proved their efficiency in terms of cardiovascular morbidity and mortality reduction. Further studies are needed to delineate the role of these drugs in the treatment of dyslipidemia in individuals with CKD.

\section{CONCLUSIONS}

Dyslipidemia is a very common complication of CKD. Disturbances in lipoprotein metabolism are evident even at the early stages of CKD and usually follow a downhill course that parallels the deterioration in renal function. Recently published studies indicate that dyslipidemia in these patients may actively participate in the pathogenesis of CVD as well as in the deterioration of renal function. Thus, we believe that the current evidence dictates the use of statins in patients with mild to moderate CKD. On the other hand, in subjects with ESRD the decision for the institution of lipidlowering therapy should be individualized. Thus, in individuals with established CVD as well as in those who run a high risk for acute pancreatitis due to severe hypertriglyceridemia the administration of hypolipidemic drugs (statins and gemfibrozil, respectively) is a safe and reasonable approach. However, it should be kept in mind that further studies are needed to delineate the clinical efficacy of these interventions.

\section{REFERENCES}

[1] Whaley-Connell AT, Sowers JR, Stevens LA, et al. CKD in the United States: Kidney Early Evaluation Program (KEEP) and National Health and Nutrition Examination Survey (NHANES) 1999-2004. Am J Kidney Dis 2008; 51: S13-S20.

[2] Yamamoto S, Kon V. Mechanisms for increased cardiovascular disease in chronic kidney dysfunction. Curr Opin Nephrol Hypertens 2009; 18: 181-8.

[3] Van Biesen W, De Bacquer D, Verbeke F, Delanghe J, Lameire N, Vanholder R. The glomerular filtration rate in an apparently healthy population and its relation with cardiovascular mortality during 10 years. Eur Heart J 2007; 28: 478-83. 
[4] Baigent C, Burbury K, Wheeler D. Premature cardiovascular disease in chronic renal failure. Lancet 2000; 356: 147-52.

[5] Sarnak MJ, Levey AS, Schoolwerth AC, et al. Kidney disease as a risk factor for development of cardiovascular disease: a statement from the American Heart Association Councils on Kidney in Cardiovascular Disease, High Blood Pressure Research, Clinical Cardiology, and Epidemiology and Prevention. Circulation 2003; 108: 2154-69.

[6] Hallan SI, Coresh J, Astor BC, et al. International comparison of the relationship of chronic kidney disease prevalence and ESRD risk. J Am Soc Nephrol 2006; 17: 2275-84.

[7] Go AS, Chertow GM, Fan D, McCulloch CE, Hsu CY. Chronic kidney disease and the risks of death, cardiovascular events, and hospitalization. N Engl J Med 2004; 351: 1296-1305.

[8] Klausen KP, Scharling H, Jensen JS. Very low level of microalbuminuria is associated with increased risk of death in subjects with cardiovascular or cerebrovascular diseases. J Intern Med 2006; 260: 231-7.

[9] Parfrey PS, Foley RN, Harnett JD, Kent GM, Murray D, Barre PE. Outcome and risk factors of ischemic heart disease in chronic uremia. Kidney Int 1996; 49: 1428-34.

[10] Foley RN, Parfrey PS, Sarnak MJ. Clinical epidemiology of cardiovascular disease in chronic renal disease. Am J Kidney Dis 1998; 32: S112-S119.

[11] van der Zee S, Baber U, Elmariah S, Winston J, Fuster V. Cardiovascular risk factors in patients with chronic kidney disease. Nat Rev Cardiol 2009; 6: 580-9.

[12] Magnus P, Beaglehole R. The real contribution of the major risk factors to the coronary epidemics: time to end the "only-50\%" myth. Arch Intern Med 2001; 161: 2657-60.

[13] Himmelfarb J, Stenvinkel P, Ikizler TA, Hakim RM. The elephant in uremia: oxidant stress as a unifying concept of cardiovascular disease in uremia. Kidney Int 2002; 62: 1524-38.

[14] Wang TJ, Gona P, Larson MG, et al. Multiple biomarkers for the prediction of first major cardiovascular events and death. N Engl J Med 2006; 355: 2631-9.

[15] Addabbo F, Mallamaci F, Leonardis D, et al. Searching for biomarker patterns characterizing carotid atherosclerotic burden in patients with reduced renal function. Nephrol Dial Transplant 2007; 22: 3521-6.

[16] Honda H, Qureshi AR, Heimburger O, et al. Serum albumin, Creactive protein, interleukin 6 , and fetuin a as predictors of malnutrition, cardiovascular disease, and mortality in patients with ESRD. Am J Kidney Dis 2006; 47: 139-48.

[17] Lewington S, Whitlock G, Clarke R, et al. Blood cholesterol and vascular mortality by age, sex, and blood pressure: a meta-analysis of individual data from 61 prospective studies with 55, 000 vascular deaths. Lancet 2007; 370: 1829-39.

[18] Tsimihodimos V, Dounousi E, Siamopoulos KC. Dyslipidemia in chronic kidney disease: an approach to pathogenesis and treatment. Am J Nephrol 2008; 28: 958-73.

[19] Kaysen GA. Lipid and lipoprotein metabolism in chronic kidney disease. J Ren Nutr 2009; 19: 73-7.

[20] Attman PO, Samuelsson O. Dyslipidemia of kidney disease. Curr Opin Lipidol 2009; 20: 293-9.

[21] Vaziri ND, Moradi H. Mechanisms of dyslipidemia of chronic renal failure. Hemodial Int 2006; 10: 1-7.

[22] Kwan BC, Kronenberg F, Beddhu S, Cheung AK. Lipoprotein metabolism and lipid management in chronic kidney disease. J Am Soc Nephrol 2007; 18: 1246-61.

[23] Fliser D, Pacini G, Engelleiter R, et al. Insulin resistance and hyperinsulinemia are already present in patients with incipient renal disease. Kidney Int 1998; 53: 1343-7.

[24] Sechi LA, Catena C, Zingaro L, Melis A, De Marchi S. Abnormalities of glucose metabolism in patients with early renal failure. Diabetes 2002; 51: 1226-32.

[25] Charlesworth JA, Kriketos AD, Jones JE, Erlich JH, Campbell LV, Peake PW. Insulin resistance and postprandial triglyceride levels in primary renal disease. Metabolism 2005; 54: 821-8.

[26] Prinsen BH, de Sain-van der Velden MG, de Koning EJ, Koomans HA, Berger R, Rabelink TJ. Hypertriglyceridemia in patients with chronic renal failure: possible mechanisms. Kidney Int Suppl 2003; 84: S121-4.

[27] Vaziri ND, Liang K. Down-regulation of tissue lipoprotein lipase expression in experimental chronic renal failure. Kidney Int 1996; 50: 1928-35.
[28] Cheung AK, Parker CJ, Ren K, Iverius PH. Increased lipase inhibition in uremia: identification of pre-beta-HDL as a major inhibitor in normal and uremic plasma. Kidney Int 1996; 49: 136071.

[29] Chan DT, Dogra GK, Irish AB, et al. Chronic kidney disease delays VLDL apoB-100 particle catabolism: potential role of apo C-III. J Lipid Res 2009; 50: 2524-31.

[30] Moberly JB, Attman PO, Samuelsson O, Johansson AC, KnightGibson C, Alaupovic P. Apolipoprotein C-III, hypertriglyceridemia and triglyceride-rich lipoproteins in uremia. Miner Electrolyte Metab 1999; 25: 258-62.

[31] Bagdade J, Casaretto A, Albers J. Effects of chronic uremia, hemodialysis, and renal transplantation on plasma lipids and lipoproteins in man. J Lab Clin Med 1976; 87: 38-48.

[32] Hirano T, Sakaue T, Misaki A, et al. Very low-density lipoproteinapoprotein CI is increased in diabetic nephropathy: comparison with apoprotein CIII. Kidney Int 2003; 63: 2171-77.

[33] Akmal M, Kasim SE, Soliman AR, Massry SG. Excess parathyroid hormone adversely affects lipid metabolism in chronic renal failure. Kidney Int 1990; 37: 854-8.

[34] Vaziri ND, Wang XQ, Liang K. Secondary hyperparathyroidism downregulates lipoprotein lipase expression in chronic renal failure. Am J Physiol 1997; 273: F925-30.

[35] Vega GL, Toto RD, Grundy SM. Metabolism of low density lipoproteins in nephrotic dyslipidemia: comparison of hypercholesterolemia alone and combined hyperlipidemia. Kidney Int 1995; 47: 579-86.

[36] Warwick GL, Packard CJ. Lipoprotein metabolism in the nephrotic syndrome. Nephrol Dial Transplant 1993; 8: 385-96.

[37] Liang K, Vaziri ND. Gene expression of lipoprotein lipase in experimental nephrosis. J Lab Clin Med 1997; 130: 387-94.

[38] Shearer GC, Stevenson FT, Atkinson DN, Jones H, Staprans I, Kaysen GA. Hypoalbuminemia and proteinuria contribute separately to reduced lipoprotein catabolism in the nephrotic syndrome. Kidney Int 2001; 59: 179-89.

[39] Attman PO, Samuelsson O, Johansson AC, Moberly JB, Alaupovic P. Dialysis modalities and dyslipidemia. Kidney Int Suppl 2003; 63: S110-S112.

[40] Mordasini R, Frey F, Flury W, Klose G, Greten H. Selective deficiency of hepatic triglyceride lipase in uremic patients. N Engl J Med 1977; 297: 1362-66.

[41] Shoji T, Nishizawa Y, Nishitani H, Yamakawa M, Morii H. Impaired metabolism of high density lipoprotein in uremic patients. Kidney Int 1992; 41: 1653-61.

[42] Huttunen JK, Pasternack A, Vanttinen T, Ehnholm C, Nikkila EA. Lipoprotein metabolism in patients with chronic uremia. Effect of hemodialysis on serum lipoproteins and postheparin plasma triglyceride lipases. Acta Med Scand 1978; 204: 211-8.

[43] Katopodis KP, Elisaf M, Balafa O, et al. Influence of the type of membrane and heparin on serum lipid parameters during a dialysis session: a pilot study. Am J Nephrol 2004; 24: 469-73.

[44] Schrader J, Stibbe W, Armstrong VW, et al. Comparison of low molecular weight heparin to standard heparin in hemodialysis/ hemofiltration. Kidney Int 1988; 33: 890-6.

[45] Wanner C, Bahner U, Mattern R, Lang D, Passlick-Deetjen J. Effect of dialysis flux and membrane material on dyslipidaemia and inflammation in haemodialysis patients. Nephrol Dial Transplant 2004; 19: 2570-5.

[46] Ottosson P, Attman PO, Knight C, Samuelsson O, Weiss L, Alaupovic P. Do high-flux dialysis membranes affect renal dyslipidemia? ASAIO J 2001; 47: 229-34.

[47] Kronenberg F, Lingenhel A, Neyer U, et al. Prevalence of dyslipidemic risk factors in hemodialysis and CAPD patients. Kidney Int Suppl 2003; 84: S113-6.

[48] Johansson AC, Samuelsson O, Attman PO, et al. Dyslipidemia in peritoneal dialysis--relation to dialytic variables. Perit Dial Int 2000; 20: 306-14.

[49] Bredie SJ, Bosch FH, Demacker PN, Stalenhoef AF, van Leusen R. Effects of peritoneal dialysis with an overnight icodextrin dwell on parameters of glucose and lipid metabolism. Perit Dial Int 2001; 21: 275-81.

[50] Babazono T, Nakamoto H, Kasai K, et al. Effects of icodextrin on glycemic and lipid profiles in diabetic patients undergoing peritoneal dialysis. Am J Nephrol 2007; 27: 409-15. 
[51] Liang K, Vaziri ND. Gene expression of LDL receptor, HMG-CoA reductase, and cholesterol-7 alpha-hydroxylase in chronic renal failure. Nephrol Dial Transplant 1997; 12: 1381-6.

[52] Vaziri ND. Molecular mechanisms of lipid disorders in nephrotic syndrome. Kidney Int 2003; 63: 1964-76.

[53] Vaziri ND, Sato T, Liang K. Molecular mechanisms of altered cholesterol metabolism in rats with spontaneous focal glomerulosclerosis. Kidney Int 2003; 63: 1756-63.

[54] Vaziri ND, Liang KH. Down-regulation of hepatic LDL receptor expression in experimental nephrosis. Kidney Int 1996; 50: 887-93.

[55] Deighan CJ, Caslake MJ, McConnell M, Boulton-Jones JM, Packard CJ. The atherogenic lipoprotein phenotype: small dense LDL and lipoprotein remnants in nephrotic range proteinuria. Atherosclerosis 2001; 157: 211-20.

[56] Vaziri ND, Liang K. Up-regulation of acyl-coenzyme A:cholesterol acyltransferase (ACAT) in nephrotic syndrome. Kidney Int 2002; 61: 1769-75

[57] Vaziri ND, Liang KH. Hepatic HMG-CoA reductase gene expression during the course of puromycin-induced nephrosis. Kidney Int 1995; 48: 1979-85.

[58] Pahl MV, Oveisi F, Khamiseh G, Vaziri ND. Intestinal absorption and biliary secretion of cholesterol in rats with nephrotic syndrome. Nephrol Dial Transplant 1998; 13: 1446-51.

[59] Rajman I, Harper L, McPake D, Kendall MJ, Wheeler DC. Lowdensity lipoprotein subfraction profiles in chronic renal failure. Nephrol Dial Transplant 1998; 13: 2281-7.

[60] Deighan CJ, Caslake MJ, McConnell M, Boulton-Jones JM, Packard CJ. Atherogenic lipoprotein phenotype in end-stage renal failure: origin and extent of small dense low-density lipoprotein formation. Am J Kidney Dis 2000; 35: 852-62.

[61] Farbakhsh K, Kasiske BL. Dyslipidemias in patients who have chronic kidney disease. Med Clin North Am 2005; 89: 689-99.

[62] Attman PO, Samuelsson OG, Moberly J, et al. Apolipoprotein Bcontaining lipoproteins in renal failure: the relation to mode of dialysis. Kidney Int 1999; 55: 1536-42.

[63] Wheeler DC. Abnormalities of lipoprotein metabolism in CAPD patients. Kidney Int Suppl 1996; 56: S41-6.

[64] Kagan A, Bar-Khayim Y, Schafer Z, Fainaru M. Heterogeneity in peritoneal transport during continuous ambulatory peritoneal dialysis and its impact on ultrafiltration, loss of macromolecules and plasma level of proteins, lipids and lipoproteins. Nephron 1993; 63: 32-42.

[65] Siamopoulos KC, Elisaf M. Is CAPD atherogenic? Perit Dial Int 1997; 17: 227-31.

[66] Kagan A, Bar-Khayim Y, Schafer Z, Fainaru M. Kinetics of peritoneal protein loss during CAPD: II. Lipoprotein leakage and its impact on plasma lipid levels. Kidney Int 1990; 37: 980-90.

[67] Kandoussi A, Cachera C, Reade R, Pagniez D, Fruchart JC, Tacquet A. Apo AIV in plasma and dialysate fluid of CAPD patients: comparison with other apolipoproteins. Nephrol Dial Transplant 1992; 7: 1026-9.

[68] Chertow GM, Burke SK, Raggi P. Sevelamer attenuates the progression of coronary and aortic calcification in hemodialysis patients. Kidney Int 2002; 62: 245-52.

[69] Milionis HJ, Elisaf MS, Tselepis A, Bairaktari E, Karabina SA, Siamopoulos KC. Apolipoprotein(a) phenotypes and lipoprotein(a) concentrations in patients with renal failure. Am J Kidney Dis 1999; 33: 1100-6.

[70] Utermann G, Menzel HJ, Kraft HG, Duba HC, Kemmler HG, Seitz C. Lp(a) glycoprotein phenotypes. Inheritance and relation to Lp(a)-lipoprotein concentrations in plasma. J Clin Invest 1987; 80: 458-65.

[71] Kronenberg F, Trenkwalder E, Lingenhel A, et al. Renovascular arteriovenous differences in $\mathrm{Lp}$ [a] plasma concentrations suggest removal of Lp[a] from the renal circulation. J Lipid Res 1997; 38: 1755-63.

[72] Kostner KM, Maurer G, Huber K, et al. Urinary excretion of apo(a) fragments. Role in apo(a) catabolism. Arterioscler Thromb Vasc Biol 1996; 16: 905-11.

[73] Haffner SM, Gruber KK, Aldrete G, Jr., Morales PA, Stern MP, Tuttle KR. Increased lipoprotein(a) concentrations in chronic renal failure. J Am Soc Nephrol 1992; 3: 1156-62.

[74] Bairaktari E, Elisaf M, Tsolas O, Siamopoulos KC. Serum Lp(a) levels in patients with moderate renal failure. Nephron 1998; 79: 367-8.
[75] Trenkwalder E, Gruber A, Konig P, Dieplinger H, Kronenberg F. Increased plasma concentrations of LDL-unbound apo(a) in patients with end-stage renal disease. Kidney Int 1997; 52: 168592.

[76] Kronenberg F, Kuen E, Ritz E, et al. Lipoprotein(a) serum concentrations and apolipoprotein(a) phenotypes in mild and moderate renal failure. J Am Soc Nephrol 2000; 11: 105-15.

[77] Kronenberg F, Neyer U, Lhotta K, et al. The low molecular weight apo(a) phenotype is an independent predictor for coronary artery disease in hemodialysis patients: a prospective follow-up. J Am Soc Nephrol 1999; 10: 1027-36.

[78] Longenecker JC, Klag MJ, Marcovina SM, et al. Small apolipoprotein(a) size predicts mortality in end-stage renal disease: The CHOICE study. Circulation 2002; 106: 2812-8.

[79] Kronenberg F, Konig P, Neyer U, et al. Multicenter study of lipoprotein(a) and apolipoprotein(a) phenotypes in patients with end-stage renal disease treated by hemodialysis or continuous ambulatory peritoneal dialysis. J Am Soc Nephrol 1995; 6: 110-20.

[80] Stenvinkel P, Heimburger O, Tuck CH, Berglund L. Apo(a)isoform size, nutritional status and inflammatory markers in chronic renal failure. Kidney Int 1998; 53: 1336-42.

[81] Stenvinkel P, Heimburger O, Paultre F, et al. Strong association between malnutrition, inflammation, and atherosclerosis in chronic renal failure. Kidney Int 1999; 55: 1899-911.

[82] Zimmermann J, Herrlinger S, Pruy A, Metzger T, Wanner C. Inflammation enhances cardiovascular risk and mortality in hemodialysis patients. Kidney Int 1999; 55: 648-58.

[83] Frischmann ME, Kronenberg F, Trenkwalder E, et al. In vivo turnover study demonstrates diminished clearance of lipoprotein(a) in hemodialysis patients. Kidney Int 2007; 71: 1036-1043.

[84] Heimburger O, Stenvinkel P, Berglund L, Tranoeus A, Lindholm B. Increased plasma lipoprotein(a) in continuous ambulatory peritoneal dialysis is related to peritoneal transport of proteins and glucose. Nephron 1996; 72: 135-44.

[85] Wanner C, Bartens W, Walz G, Nauck M, Schollmeyer P. Protein loss and genetic polymorphism of apolipoprotein(a) modulate serum lipoprotein(a) in CAPD patients. Nephrol Dial Transplant 1995; 10: 75-81.

[86] Wanner C, Rader D, Bartens W, et al. Elevated plasma lipoprotein(a) in patients with the nephrotic syndrome. Ann Intern Med 1993; 119: 263-9.

[87] de Sain-van der Velden MG, Reijngoud DJ, Kaysen GA, et al. Evidence for increased synthesis of lipoprotein(a) in the nephrotic syndrome. J Am Soc Nephrol 1998; 9: 1474-81.

[88] Kontush A, Chapman MJ. Antiatherogenic small, dense HDL-guardian angel of the arterial wall? Nat Clin Pract Cardiovasc Med 2006; 3: 144-53.

[89] Despres JP, Lemieux I, Dagenais GR, Cantin B, Lamarche B. HDL-cholesterol as a marker of coronary heart disease risk: the Quebec cardiovascular study. Atherosclerosis 2000; 153: 263-72.

[90] Attman PO, Samuelsson O, Alaupovic P. Lipoprotein metabolism and renal failure. Am J Kidney Dis 1993; 21: 573-92.

[91] Vaziri ND, Deng G, Liang K. Hepatic HDL receptor, SR-B1 and Apo A-I expression in chronic renal failure. Nephrol Dial Transplant 1999; 14: 1462-6.

[92] Vaziri ND, Liang K, Parks JS. Down-regulation of hepatic lecithin:cholesterol acyltransferase gene expression in chronic renal failure. Kidney Int 2001; 59: 2192-6.

[93] Guarnieri GF, Moracchiello M, Campanacci L, et al. Lecithincholesterol acyltransferase (LCAT) activity in chronic uremia. Kidney Int Suppl 1978; S26-S30.

[94] Kimura H, Miyazaki R, Imura T, et al. Hepatic lipase mutation may reduce vascular disease prevalence in hemodialysis patients with high CETP levels. Kidney Int 2003; 64: 1829-37.

[95] Dirican M, Akca R, Sarandol E, Dilek K. Serum paraoxonase activity in uremic predialysis and hemodialysis patients. J Nephrol 2004; 17: 813-8.

[96] Liberopoulos EN, Papavasiliou E, Miltiadous GA, et al. Alterations of paraoxonase and platelet-activating factor acetylhydrolase activities in patients on peritoneal dialysis. Perit Dial Int 2004; 24 : 580-9.

[97] Blankestijn PJ, Vos PF, Rabelink TJ, van Rijn HJ, Jansen H, Koomans HA. High-flux dialysis membranes improve lipid profile in chronic hemodialysis patients. J Am Soc Nephrol 1995; 5: $1703-8$. 
[98] Docci D, Capponcini C, Mengozzi S, Baldrati L, Neri L, Feletti C. Effects of different dialysis membranes on lipid and lipoprotein serum profiles in hemodialysis patients. Nephron 1995; 69: 323-6.

[99] Jung K, Scheifler A, Schulze BD, Scholz M. Lower serum highdensity lipoprotein-cholesterol concentration in patients undergoing maintenance hemodialysis with acetate than with bicarbonate. Am J Kidney Dis 1995; 25: 584-8.

[100] Koch M, Kutkuhn B, Trenkwalder E, et al. Apolipoprotein B, fibrinogen, HDL cholesterol, and apolipoprotein(a) phenotypes predict coronary artery disease in hemodialysis patients. J Am Soc Nephrol 1997; 8: 1889-98.

[101] Degoulet P, Legrain M, Reach I, et al. Mortality risk factors in patients treated by chronic hemodialysis. Report of the Diaphane collaborative study. Nephron 1982; 31: 103-10.

[102] Shlipak MG, Fried LF, Cushman M, et al. Cardiovascular mortality risk in chronic kidney disease: comparison of traditional and novel risk factors. JAMA 2005; 293: 1737-45.

[103] Kalantar-Zadeh K, Block G, Humphreys MH, Kopple JD. Reverse epidemiology of cardiovascular risk factors in maintenance dialysis patients. Kidney Int 2003; 63: 793-808.

[104] Lowrie EG, Lew NL. Death risk in hemodialysis patients: the predictive value of commonly measured variables and an evaluation of death rate differences between facilities. Am J Kidney Dis 1990; 15: 458-82.

[105] Iseki K, Yamazato M, Tozawa M, Takishita S. Hypocholesterolemia is a significant predictor of death in a cohort of chronic hemodialysis patients. Kidney Int 2002; 61: 1887-93.

[106] Liu Y, Coresh J, Eustace JA, et al. Association between cholesterol level and mortality in dialysis patients: role of inflammation and malnutrition. JAMA 2004; 291: 451-9.

[107] Kilpatrick RD, McAllister CJ, Kovesdy CP, Derose SF, Kopple JD, Kalantar-Zadeh K. Association between serum lipids and survival in hemodialysis patients and impact of race. J Am Soc Nephrol 2007; 18: 293-303.

[108] K/DOQI clinical practice guidelines for management of dyslipidemias in patients with kidney disease. Am J Kidney Dis 2003; 41: I-91.

[109] Executive Summary of The Third Report of The National Cholesterol Education Program (NCEP) Expert Panel on Detection, Evaluation, And Treatment of High Blood Cholesterol In Adults (Adult Treatment Panel III). JAMA 2001; 285: 2486-97.

[110] Tonelli M, Bohm C, Pandeya S, Gill J, Levin A, Kiberd BA. Cardiac risk factors and the use of cardioprotective medications in patients with chronic renal insufficiency. Am J Kidney Dis 2001; 37: 484-9.

[111] Harris K, Thomas M, Short C, Moore R. Assessment of the efficiency of treatment of dyslipidaemia in renal outpatients. J Nephrol 2002; 15: 263-9.

[112] Baigent C, Keech A, Kearney PM, et al. Efficacy and safety of cholesterol-lowering treatment: prospective meta-analysis of data from 90, 056 participants in 14 randomised trials of statins. Lancet 2005; 366: 1267-78.

[113] Lemos PA, Serruys PW, de Feyter P, et al. Long-term fluvastatin reduces the hazardous effect of renal impairment on four-year atherosclerotic outcomes (a LIPS substudy). Am J Cardiol 2005; 95: 445-51.

[114] Tonelli M, Moye L, Sacks FM, Kiberd B, Curhan G. Pravastatin for secondary prevention of cardiovascular events in persons with mild chronic renal insufficiency. Ann Intern Med 2003; 138: 98104.

[115] Tonelli M, Isles C, Curhan GC, et al. Effect of pravastatin on cardiovascular events in people with chronic kidney disease. Circulation 2004; 110: 1557-63.

[116] Holdaas H, Wanner C, Abletshauser C, Gimpelewicz C, Isaacsohn J. The effect of fluvastatin on cardiac outcomes in patients with moderate to severe renal insufficiency: a pooled analysis of doubleblind, randomized trials. Int J Cardiol 2007; 117: 64-74.

[117] Shepherd J, Kastelein JJ, Bittner V, et al. Intensive lipid lowering with atorvastatin in patients with coronary heart disease and chronic kidney disease: the TNT (Treating to New Targets) study. J Am Coll Cardiol 2008; 51: 1448-54.

[118] Koren MJ, Davidson MH, Wilson DJ, Fayyad RS, Zuckerman A, Reed DP. Focused atorvastatin therapy in managed-care patients with coronary heart disease and CKD. Am J Kidney Dis 2009; 53: 741-50.

[119] MRC/BHF Heart Protection Study of cholesterol lowering with simvastatin in 20, 536 high-risk individuals: a randomised placebocontrolled trial. Lancet 2002; 360: 7-22.

[120] Sever PS, Dahlof B, Poulter NR, et al. Prevention of coronary and stroke events with atorvastatin in hypertensive patients who have average or lower-than-average cholesterol concentrations, in the Anglo-Scandinavian Cardiac Outcomes Trial--Lipid Lowering Arm (ASCOT-LLA): a multicentre randomised controlled trial. Lancet 2003; 361: 1149-58.

[121] Navaneethan SD, Pansini F, Perkovic V, et al. HMG CoA reductase inhibitors (statins) for people with chronic kidney disease not requiring dialysis. Cochrane Database Syst Rev 2009; 2: CD007784.

[122] Seliger SL, Weiss NS, Gillen DL, et al. HMG-CoA reductase inhibitors are associated with reduced mortality in ESRD patients. Kidney Int 2002; 61: 297-304.

[123] Mason NA, Bailie GR, Satayathum S, et al. HMG-coenzyme a reductase inhibitor use is associated with mortality reduction in hemodialysis patients. Am J Kidney Dis 2005; 45: 119-26.

[124] Goldfarb-Rumyantzev AS, Habib AN, Baird BC, Barenbaum LL, Cheung AK. The association of lipid-modifying medications with mortality in patients on long-term peritoneal dialysis. Am J Kidney Dis 2007; 50: 791-802.

[125] Wanner C, Krane V, Marz W, et al. Randomized controlled trial on the efficacy and safety of atorvastatin in patients with type 2 diabetes on hemodialysis (4D study): demographic and baseline characteristics. Kidney Blood Press Res 2004; 27: 259-66.

[126] Wanner C, Krane V, Marz W, et al. Atorvastatin in patients with type 2 diabetes mellitus undergoing hemodialysis. N Engl J Med 2005; 353: 238-48.

[127] Fellstrom BC, Jardine AG, Schmieder RE, et al. Rosuvastatin and cardiovascular events in patients undergoing hemodialysis. N Engl J Med 2009; 360: 1395-407.

[128] Shoji T, Nishizawa Y. Plasma lipoprotein abnormalities in hemodialysis patients--clinical implications and therapeutic guidelines. Ther Apher Dial 2006; 10: 305-15.

[129] Ritz E, Wanner C. Lipid changes and statins in chronic renal insufficiency. J Am Soc Nephrol 2006; 17: S226-30.

[130] Backes JM, Gibson CA, Ruisinger JF, Moriarty PM. Fibrates: what have we learned in the past 40 years? Pharmacotherapy 2007; 27: 412-24.

[131] Brown WV. Expert commentary: the safety of fibrates in lipidlowering therapy. Am J Cardiol 2007; 99: 19C-21C.

[132] Davidson MH, Armani A, McKenney JM, Jacobson TA. Safety considerations with fibrate therapy. Am J Cardiol 2007; 99: 3C$18 \mathrm{C}$.

[133] Tonelli M, Collins D, Robins S, Bloomfield H, Curhan GC. Gemfibrozil for secondary prevention of cardiovascular events in mild to moderate chronic renal insufficiency. Kidney Int 2004; 66 : 1123-30.

[134] Davidson MH, Stein EA, Bays HE, et al. Efficacy and tolerability of adding prescription omega-3 fatty acids $4 \mathrm{~g} / \mathrm{d}$ to simvastatin 40 $\mathrm{mg} / \mathrm{d}$ in hypertriglyceridemic patients: an 8-week, randomized, double-blind, placebo-controlled study. Clin Ther 2007; 29: 135467.

This is an open access article licensed under the terms of the Creative Commons Attribution Non-Commercial License (http://creativecommons.org/licenses/ by-nc/3.0/) which permits unrestricted, non-commercial use, distribution and reproduction in any medium, provided the work is properly cited. 